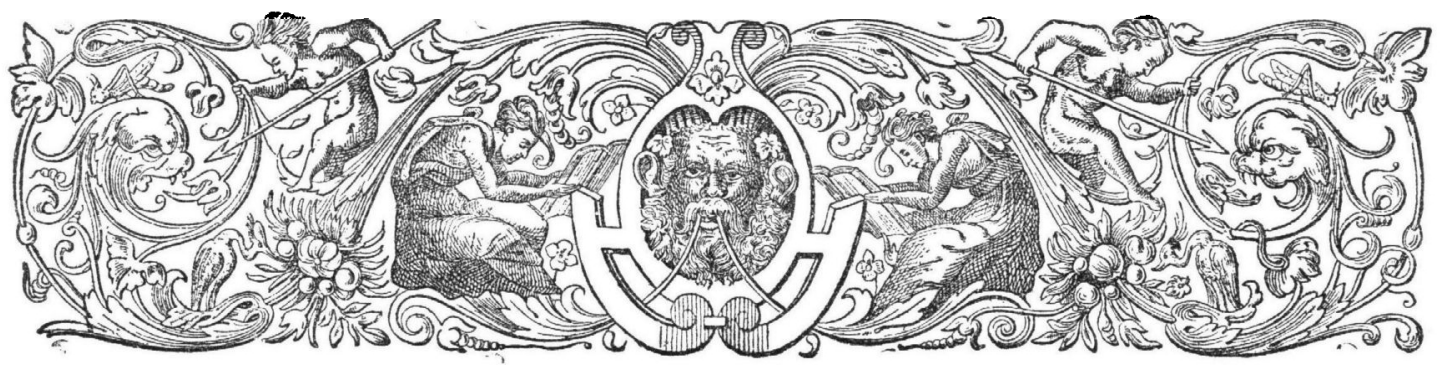

\title{
DE PORTRETTEN, AFKOMSTIG VAN HET HUIS HONSELAERSDIJK, IN 'S RIJKS MUSEUM TE AMSTERDAM
}

DOOR

\author{
G. MURRAY BAKKER.
}

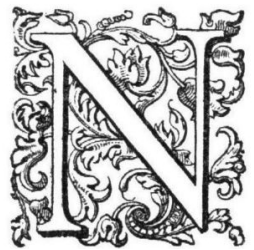

ADAT reeds herhaaldelijk twijfel bij mij was gerezen, of de Catalogus van het Rijksmuseum wel eene juiste persoonsaanduiding gaf van het vijftigtal portretten, dat zich in de zaal der Admiralen bevindt, afkomstig van het Huis Honselaersdijk, voorstellende vorsten uit het Huis van Oranje-Nassau en eenige voorname krijgsoversten uit het laatst der 16 e en den aanvang der $17^{\text {e euw }}$, besloot ik tot een nacier onderzoek. De vruchten daarvan heb ik in de volgende bladzijden neergelegd. Voorloopig heb ik mij daarbij bepaald tot de portretten der krijgsoversten, niet tot het Huis van Oranje-Nassau behoorende. De portretten van leden van dat Huis behandel ik wellicht in cen volgend artikel.

Reeds sedert de oprichting van het Koninklijk Museum in 1808 maken deze portretten deel uit van de verzameling. $\mathrm{Zij}$ zijn afkomstig van het Huis Honselaersdijk, een lustslot der Oranjes, en werden denkelijk op last van de Prinsen MaUrits en Frederik HeNDrik geschilderd, die hun paleis wenschten te 
sieren met de beeltenissen ${ }^{1}$ ) der mannen, wier onverschrokken moed en zelfopofferende trouw het basalt, en wier bloed het cement was, waarvan het hechte Staatsgebouw der Vereenigde Nederlanden werd opgetrokken.

De hier besproken portretten zijn grootendeels van de hand van JAN Anthonisz VAN RAVESTEyn, hetzij oorspronkelijk, hetzij naar Mierevelt. No. 983 van den Catalogus, voorstellende "Coronel Wy'ten HoGHE", is door Paulus MOReelse. Het zijn allen borstbeelden, meest in driekwart en naar de rechterzijde gewend, op paneel, en hoog $29 \mathrm{cM}$., breed $25 \mathrm{cM}$. In vergulde letters zijn de namen der afgebeelde personen er op geschilderd. Deze namen zijn echter deels onvolledig, deels waarschijnlijk door overschildering van den achtergrond verminkt. Toch is de aanduiding voldoende om, in verband met het uit het 'kostuum vrij nauwkeurig te bepalen tijdstip, waarop oorspronkelijk de afgebeelde persoon geschilderd is, uit te maken wie de portretten voorstellen. Want ofschoon dit kostuum zieh slechts bepaalt tot cen gedeelte van het borstkuras en een linnen of kanten halskraag, is deze laatste genoeg aan mode onderhevig, om op enkele iaren na tot eene vrij zekere tijdsbepaling te kunnen komen.

De oudste Catalogus van $\mathbf{I} 809$ vermeldt alleen de namen gelijk zij op de portretten staan. Evenzoo de uitgaven van $1816,18,21$ en 25 . De 6 a druk van I 826 zegt: 48 stuks portretten van prinsen van Oranje en graven van Nassau en andere voorname personen." In de uitgaven van $1828,30,32,33,36,37$, 4I, 43, 46, 49 en 53 worden zij eveneens collectief onder één nummer vermeld. De „Beschrijving der schilderijen" van 1858 geeft weer de namen, zooals de catalogus van 1809 , en evenzoo de uitgaven van $1859,61,70,72$ en 76 . Eerst de officieele "Beschrijving der schilderijen van het Rijksmuseum te Amsterdam" van I 880 geeft in de bijgevoegde "Historische aanteekeningen" eene nadere aanduiding en korte levensbeschrijving van de afgebeelde personen, welke beschrijving in de daarop gevolgde bewerking van den Catalogus door dr. A. BREdius in uittreksel is medegedeeld.

Wij zullen daarom den Catalogus van 1880 als punt van uitgang voor onze nadere beschouwingen nemen, en achtereenvolgens de portretten behandelen,

1) Een paar fortretjes, blijkbanr tot dezelfde serie behoord hebbende, zag ik eenige jaren geleden op het Kasteel Rheinstein nabij Bingen, dat het eigendom is van Prins George van Pruisen. Zij zijn waarschijnlijk van de anderen gescheiden, toen Honselaersdijk aan FREDERIK I en FREDERIK II van Pruisen toebehoorde.

In het Mauritshuis bevindt zich eene reeks van 24 levensgroote knjestukken, op één na (no. 457) allen van de hand van Jan ANTHONisz van Ravesteyn, en allen voorstellende hoofdofficieren van Prins MauRits, geschilderd tusschen de jaren I6II en I624. Jammer genoeg zijn hunne namen tot heden onbekend. Van een enkele slechts weet men die, n.l. van Kolonel Nicolabs SMelsinc, van wien zich ook twee portretten in het Rijksmuseum bevinden, het eene een kniestuk, het andere behoorende tot de serie die wij hier bespreken.

Eene andere serie krijgsoversten bevindt zich te Hoorn in het Westfriesch Muscum en op het Stadhuis aldaar. 
die in dien Catalogus onder no. 43 I zijn aangeduid met de letters $h \hbar, m m, n n$, $o o, p p, q q, r r, s s, t t, u u, v v$.

De hier medegedeelde levensbizonderheden zijn grootendeels geput uit officiëele stukken, zich bevindende in het Rijksarchief te 's Hage, en dikwijls afwijkend van hetgeen in biographische verzamelwerken of monographieën omtrent de verschillende personen wordt medegedeeld. Enkele hunner, zooals b.v. BroG en HENDERSON, waren door verloop van eeuwen reeds geheel in vergetelheid geraakt, zoodat men nauwelijks hunne namen meer kende.

No. 43 I hh (Cat. 1887 no. 1183). Het opschrift luidt: "Mons'. Chatillon Marcsc. de France."

De Catalogus noemt hem GASPARD DE COLIGNy, graaf van Châtillon, zoon van FRANÇOIS, den broeder van den beroemden admiraal van Frankrijk, die in den Bartholomeusnacht vermoord werd.

Dit is minder juist. Gaspard DE Chatillon, graaf van Colligny, was de zoon van François de Chatillon graaf van Colligny en Marguérite d'Ailly de PÉquigny, welke FrançOIS de derde zoon was van den grooten Admiraal GASPARD en van Charlotte de Laval. De admiraal was dus Gaspard's grootvader.

Den 26 Juli I 584 geboren, begaf hij zich op het voetspoor van zijn één jaar ouderen broeder HENRI, die Io September I60I, als kolonel van het regiment fransche hulptroepen in staatschen dienst, in het beleg van Ostende gesneuveld was, naar de Nederlanden. In December I602 kwam hij hier te lande aan met zijne tante LOUISE DE CollignY, weduwe van Prins Willem I, en verkreeg den I 8 November 1603 van de Staten-Generaal commissie als kolonel over een fransch regiment. De Igjarige kolonel wordt in die commissie ${ }^{1}$ ) genoemd : „Seigneur GASPARD comte de Colligny, Seigneur de Chastillon, Admiral de Guienne, capne de cincquante hommes d'armes des ordonnances du Roy, et Gouverneur pour Sa $\mathrm{Ma}^{\text {te }}$ de sa ville de Montpellier", al welke waardigheden vroeger door zijn broeder HENRI ${ }^{2}$ ), het petekind van Koning HENRI IV, bekleed waren, en na diens sneu. velen door den Koning op GASPARD werden overgedragen. Vele jaren bleef hij in dienst der Staten, en onderscheidde $z$ ich bij menige gelegenheid. Zijn levensloop is bekend genoeg, om daarop hier niet verder te behoeven in te gaan.

No. 43 I $m m$ (Cat. I 887 no. I 85 ). Het opschrift luidt: Monsicur Viles Maresc dy Camp."

Dit is het portret van den veldmaarschalk JOOST DE SOETE Heer van Villers.

1) Commissieboek Staten-Generaal I586-I625 f. 235 (Rijksarchief).

2) Deze was reeds op rojarigen leeftijd Admiraal van Guyenne. 
De Catalogus zegt dat hij, na in April I587 uit de spaa ssche krijgsgevangenschap geraakt te zijn, tot veldmaarschalk werd aangesteld, om ie bewijzen dat het vertrouwen in hem niet verzwakt was.

Hij was echter reeds in 1585 tot veldmaarschalk benoemd, toen zijn voorganger de veldmaarschalk FRANÇOIS DE LA NOUE na 5 jarige krijgsgevangenschap losgelaten werd, onder voorwaarde dat hij niet meer in de Nederlanden tegen Spanje zou dienen, en er dus geen kans meer bestond, dat de dappere „Brasde-fer" voor deze landen opnieuw den degen zoude voeren.

Uit de hem als veldmaarschalk op 9 Augustus 1588 wederom verleende commissie, voorkomende in het commissieboek van den Raad van State (Rijksarchief, blijkt dat dan ook. Wij lezen daarin dat zijne aanstelling een gevolg . is van "de goede kennisse ende gedachtenisse die wij hebben vanden goeden dienst, vromicheyt ende cloucheyt bij den Edelen ende gestrenghen Heere Joos DE ZOETE Ridder Heere van Villers etc. hyer voormaels inden zelven staet ende officie van Veltmaerschalck voor zyner lanckduyrighe gevanckenisse gedaen ende daeromme volcomel. vertrouwende tzijner cloucheyt."

No. 43 I $n n$ (Cat. I 887 no. I I 86). Het opschrift luidt: Monsr. de Houtin."

De Catalogus noemt hem PHILIPS DE SoETE, Heer van Hautain, de broeder van den voorgaande, die, tijdens het beleg van Antwerpen in 1585 van den Kouwensteinschen dijk sprong, liever dan zich over te geven.

De platte kanten kraag, die omstreeks 16 I5-20 gedragen werd, laat echter geen twijfel over, dat wij hier een ander lid van dat geslacht voor ons zien.

In den aanvang der $I 7^{\mathrm{e}}$ eeuw leefden twee leden dier familie, die beide den afgebeelden Monst. DE HaUtain zouden kunnen voorstellen, n.1. FiLips en Willem de Soete de Laeke van Hautain, zonen van Alexander Heer VAN HAUTAIN (onderteekenaar van het verbond der edelen, trouw vriend van Oranje en gouverneur van Walcheren in 1576 ) en MARGARETHA VAN BERCHEM. Beiden werden Heer van Hautain genoemd in officiëele stukken van dien tijd. Beiden waren achtereenvolgens gouverneur van Sluis, en werden in de St. Jans. kerk aldaar begraven, waar voor elk hunner een prachtig monument werd opgericht. Op dat van WILLFM waren hij en zijne gemalin in marmer levensgroot uitgehouwen. De graftombe voor PHILIPS bevatte slechts eene inscriptie. Jammer genoeg gingen deze en andere monumenten, waaraan die kerk zoo rijk was, bij den brand van $\mathrm{r} 8 \mathrm{I}$ I, verloren.

De gelegenheid, om het portret met het marmeren beeld op de graftombe van WILleM VAN HAdTAIN te vergelijken, bestond dus niet meer. Ik vond echter vermeld, dat van die tombe nog enlele fragmenten, waaronder een 
levensgroot marmeren manshoofd, in de Oudheidskamer te Sluis bewaard werden. De Heer Burgemeester van Sluis, aan wien ik eene schets naar het portret toezond, was wel zoo goed dit te vergelijken met den marmeren kop van WILLEM vaN HaUtain's beeltenis, en deelde mij mede, dat portret en marmeren manshoofd denzelfden persoon voorstellen.

Wij kunnen dus als zeker aannemen, dat no. $43 \mathrm{I} n n$ het portret is van Willey de SOETE dE LAEke Heer van Hautain. In Januari I602 werd hij luitenant-Admiraal van Zeeland. DuYcK (Journael III p. 227) noemde hem toen „een jongman noch sonder baert ende experientie ter zee". Reeds in I604 onderscheidde hij zich bij de verovering van Sluis, en in Juni van het volgend jaar bracht hij in het Kanaal eene nederlaag toe aan de spaansche schepen, die versche troepen in hadden voor SpINola. De Staten-Generaal vereerden hem deswege met een zeer kostbare gouden keten en gedenkpenning ${ }^{1}$ ):

„Te betalen aen JAN CORNelisz goutsmith de somme van I 383 ponden ro schell. van 40 grootten tpondt over 't goud ende 't fatsoen vande gouden kettinge bij hem gemaeckt ende gelevert ende den gouden medaille vande veroveringhe van Sluys, daermede den Heere van HaUltain vereert is geworden voor de extraordinaris diensten die denselven van dit jaer ter zee gedaen ende het rencontre dat hij mette Spaensche vlote gehadt heeft". (Ordonnantieboek der Staten-Generaal 27 December I605).

Voor verdere levensbizonderheden van hem verwijs ik naar KoK, Vaderlandsch Woordenboek i. v., dat eene uitvoerige en vrij nauwkeurige levensbeschrijving van hem bevat. Alleen, waar deze zegt, dat HAULTAIN spoedig na zijn aftreden in I627 als Admiraal van Zeeland gestorven is, vermeld ik, dat hij nog daarna zijn op I 5 November 1626 gestorven broeder PHILIPs is opgevolgd als gouverneur van Sluis, luitenant van Prins FREDERIK HENDRIK over alle steden, sterkten en garnizoenen in Vlaanderen onder de gehoorzaamheid van de H.M. Heeren StatenGeneraal der Vereenigde Nederlanden, en kolonel van een regiment voetvolk. Hij overleed 26 September 1637 .

Hij was gehuwd met Olimpia DE HerTaing, dochter van Willem DE Hertaing, Heer van Marquette, gouverneur van Bergen-op-Zoom, onderteekenaar van het verbond der edelen, en AnNa DE LEvin. Zij overleed 5 April i 636.

No. 43 I 00 . (Cat. I 887 No. I I 87). Het opschrift luidt: Monsr. De Temple. Gelijk de Catalogus vermeldi, is dit het portret van OLIVIER VAN DEN TeMpel (of: TyMPEL), Heer van Corbeecke. Hij was de zoon van Johan vaN

1) Ten onrechte vermelden de biographen van Filips vas Hautais, dat aan dezen de gouden keten zou vereerd zijn. 
DEN TyMPel Heer van Corbeecke, die denkelijk tot de verbonden edelen behoorde, en een trouw vriend en bondgenoot van Prins Willem I was. Olivier bevond zich reeds sedert 1573 in dienst van den lande, werd in 1574 kapitein, en twee jaren later tot kolonel bevorderd. Den 22 November 1576 trok hij aan het hoofd zijner troepen Brussel binnen, en werd in Juni 1579 door Aartshertog Matrias van Oostenrijk tot gouverneur dier stad benoemd. In dat commando deed hij zich kennen als een man van zeldzame wilskracht en moed, en een trouw aanhanger van den Prins, en verijdelde hij een aanslag op de stad door de Spanjaarden onder graaf PHILIPS van EGmont. Hij voerde het bevel binnen Brussel, totdat de stad zich in 1585 na een heldhaftig beleg aan den Hertog van PARMA moest overgeven. Nadat lastertongen te vergeefs getracht hadden het vertrouwen in hem te schokken, kwam hij bij het veldleger van Prins MAURITs, en nam deel aan alle belangrijke krijgsbedrijven van zijn tijd. Nieuwpoort, Ostende, en waar meer krijgsroem te behalen viel, overal meldt de historie zijn naam met eere. Den 28 Juli 597 werd hij benoemd tot voorzitter van den krijgsraad (Commissie- ' boek Raad van State, Rijksarchief).

Tijdens het beleg van 's-Hertogenbosch, den $3^{\text {en }}$ October I603, toen hij met den markies DE MALESPINA van een maaltijd bij Prins MaURITs naar zijn kwartier terugkeerde, werden beide getroffen door een kanonskogel, die hunne paarden doodde, en waardoor hun beiden de beenen afgeschoten werden. De Heer van Corbeecke overleed nog denzelfden avond, oud bijna 60 jaren, en werd den 20 October $\mathrm{I}_{603}$ in de Groote Kerk te Heusden met groote staatsie begraven, begeleid door Prins Maukits, Graaf Willem van Nassau, den Vorst van Animat en andere voorname krijgsoversten. BOR (Gelegentheyt van 's Hertogen-Bosch, 's-Hage I630 p. 139) noemt hem ,een fraeij ende couragieus man", en geeft het volgend chronogram op zijn overlijden:

OLIVIer Van den tIIMpeL heer Van CorbeeCk stoVt soLdaat/ VVIerdt beII zIIn beenen afghesChoten/dIes hII hIer 't LeVen VerLaet.

No. 43 I $p p$. (Cat. I 887 no. I I 88 ). Het opschrift luidt: Monsr. De Hama.

In den Catalogus van 1880 wordt het niet onwaarschijnlijls genoemd, dat bij het overschilderen van den achtergrond het opschrift verminkt is, en dat er gestaan zou hebben : "MONSr. DE HANIA", zoodat dit portret zou voorstellen een der drie edelen uit het geslacht HANIA, die zich in 1566 bij de verbonden edelen aansloten.

Deze attributie komt mij zeer onwaarschijnlijk voor. Wij mogen toch Oud-Holland, 1898. 
gerust aannemen, dat de hier afgebeelde persoon ${ }^{1}$ ) wiens portret op last van Prins MAURITS geschilderd werd, eene bekende figuur in zijn tijd is geweest. En van de drie HANIA's is al zeer weinig bekend. $Z$ ij schijnen de wijk genomen te hebben uit Friesland, na hunne verbanning door ALva. Of zij verder een werkzaam aandeel in den.worstelstrijd tegen Spanje gehad hebben, blijkt tot heden uit geen enkel feit. Dat wij hier dus een der drie HaNiA's voor ons zouden zien, schijnt mij niet zeer aannemelijk.

Bovendien is het opschrift "MoNSr. DE HAMA" niet in minusculen geschreven - waardoor de verandering van HANIA in HAMA, door de weglating der punt boven de i, zeer verklaarbaar zou geweest zijn - doch in majusculen: "HAMA". Er zou dus voor de twee letters $\mathrm{N}$ en $\mathrm{I}$ ééne letter $\mathrm{M}$ in de plaats gekomen zijn. Ook dit maakt de veronderstelling van den Catalogus is8o onwaarschijnlijk. ${ }^{2}$ )

Ik waag het echter eene andere conjectuur te maken, die mij aannemelijker voorkomt, namelijk dat het opschrift oorspronkelijk geluid zal hebben: "MoNsr. DF. FAMA". Tegenover deze conjectuur vervallen de bezwaren, die tegen de eerstc bestonden. Er is dan slechts ééne letter van het opschrift verminkt. En de afgebeelde persoon is een der vertrouwde vrienden van Prins WiLLEM I.

Charles DE LEVIN, Ridder, Heer van Famars, Lonsart en Foricourt, algemeen bekend als de Heer van FAMARS of FAMA ${ }^{3}$ ) was eene der heldenfiguren uit den tachtigjarigen oorlog. Hij stamde uit een oud, aanzienlijk geslacht uit het Kamerijksche. (Reeds in het jaar I007 doet FOULQUE DE LEVIN afstand van de aanspraken, die bij kon doen gelden op het graafschap Cambresis.)

Zoon van JAQUeS DE LEvin, Heere van Lonsart, de la Couture, de Marets, gouverneur van het kasteel van Kamerijk, en van Pinlippine de LAmelin. Vrouwe van FaMARs en Foricourt, was ChaRles DE LEVIN, ondanks zijn jeugdigen leeftijd, een der voornaamste hoofden van het compromis der edelen. Hij was een der I 3 afgevaardigden van den adel, die met de landvoogdes onderhandelden, ten gevolge waarvan het voorloopig verdrag van 23 Augustus I 566 gesloten werd, en onderteekende als zoodanig den reversaalbrief van 25 Augustus I 566. Door Alva gebannen, bleef hij een trouw aanhanger van ORANJe, dien hij afwisselend als diplomaat en als legeraanvoerder diende. Den 24 Mei 1572 verraste hij met

1) Het costuum is van omstreeks $15^{85}-90$. Wanneer het portret dus werkelijk door JAN ANTIONIsZ VAN RAVESTEYN geschilderd is, moet het naar een ander portret genomen zijn, daar van een oorsprozkelijk werk van hem uit dien tijd nog geen sprake kan zijn. Dezelfde opmerking geldt voor no. $43 \mathrm{I} \mathrm{mm.}$

s) De Catalogus van 1887 vermeldt niet eens meer het corrupte opschrift Monsr. de Hama, duch zegt reeds, dat het luidt: Monsr. de Hania"(!)

3) VAn Meteren, Vondel (waar hij onder de krijgsoversten voor Grol in i627 zijn zoon GuiLlaume noemt) en anderen schrijven : FAMA. 
hulp van den dapperen FrançoIS DE LA NOUE de stad Valenciennes. In Jamuari I573 is hij te Embden, wachtende op eene gelegenheid om over ijs naar Holland over te steken. (Groen v. Prinsterer, Archives de la Maison d' Orange Nassau, I Serie t. IV p. 45). In Augustus I 577 vinden wij hem als diplomatiek agent van ORANJE, met eene geheime zending belast bij koningin ELISABETH, in Engeland (Groen, Archives t. VI p. I33.)

Den $2^{\text {en }}$ Januari 1580 werd hij op hoogst eervolle wijze door den Prins aangesteld tot generaal der ruiterij. De commissie bevat, onder meer, het volgende: „Comme nous trouvons convenir et necessaire que les compagnies des gens de guerre à cheval, presentement esparses par la Flandre, soient rangées et conduites par ung Chef experimenté tant pour le service du public en general, que principalement pour la garde de la frontiere dudit pays de Flandre contre les incursions des ennemis, et mesmement psur secourir le Tournesis à present assailli par les dis ennemis. Pour ce est il que pour la bonne cognoissance, que nous avons de l'experience de Sieur Charles de Levin Sr. de Famars etc. la plaine confiance qu' avons de sa vertu, diligence et vigilance, nous l'avons prié et requis, prions et requerons par cestes, de vouloir entreprendre la charge desdites compagnies etc. et aultrement faire ce que ung bon general et Chef de la Cavaillerie, doit et est obligé de faire". Den 9 April 1580 vermeesterde hij aan het hoofd zijner ruiters, met behulp van OLIVIER VAN DEN TyMPEL, gouverneur van Brussel, en een engelsch regiment in statendienst onder kolonel JOHN NORRIS, de stad Mechelen ${ }^{1}$ ), waarover hij door Aartshertog MatThias van Oostenrijk, op advies van ORANJE, tot gouverneur werd aangesteld. Hier wist hij het gezag te handhaven tot I9 Juli I585, toen hij, geen kans op ontzet ziende, en door uithongering gedwongen, de stad aan PARMA moest overgeven.

Kort hierop werd hij door de Staten Generaal benoemd tot generaal der artillerie; en het is als zoodanig dat hij voor Ootmarsum sneuvelde. "Den XXXen July I 592 heel vrouch werden dvoorsz. 3 halve canons geplaetst voor Oetmaerssen ende mette selve geschooten synde 2 voleen, is terstont daeraen de Heere van Famars Generael van de artillerie der vereenichde Nederlanden, die ter sijden vuijt getreden was om door een doornen heijninge te mogen sien wat effect het geschut dede, door de cop geschooten, dat hij terstont doot bleeff tot groote droeffenisse ende naerdeel van den heelen leeger" (DuYCK, Journael I, P. II I). $\mathrm{Hij}$ werd begraven in de Groote Kerk te Heusden, over welke stad hij sedert I 588 gouverneur was geweest.

1) De stad werd, ondanks het verzet van Famars en V. D. TYMPEL, door de Engelschen, die verre in de meerderheid waren, een maand lang geplunderd en gebrandschat, VAN METEREN deelt mede, dat de klokken en het uurwerk uit den toren werden gehaald, ja, dat honderden grafzerken op schepen naar Engeland werden overgebracht. 
Groot was de deelneming in het verlies van den dappere, die, goed en bloed op het altaar des vaderlands ten offer brengende, zijne weduwe CATHARINA HinckaERT, vrouwe van Ohain, Cerfontaines en Nattignies in kommervolle omstandigheden achterliet. Op dringende aanbeveling van Prins MaURITS en den Raad van State, om ten aanzien van ,die goede diensten bij den Heere van Famars den lande gedaen, zijne weduwe ende kinderen soo gunstelyck na hare qualiteit te tracteeren, dat andere daerdoor geencourageert werden met gelycke getrouwicheyt als den overledene den Lande te dienen," ${ }^{1}$ ) werd haar en hare kinderen een pensioen toegekend, een buitengewoon iets in die dagen, toen de berooide staat der geldmiddelen zelfs niet de behoorlijke betaling der troepen veroorloofde. En toen haar in November daarop nog een zoon geboren werd, vaardigden de Staten Generaal twee gecommitteerden af om van hunnentwege over den doop te staan, en werd besloten ,dat men vanwege de Generaliteyt tselve kindt (weesende een soonke), daarmede het eerlyck in den Lande dienst mach opghetoogen werden, sal toelegghen een lyffrente van $250 \mathrm{gl}$. jaerlycx" 2).

Beide zonen, zoowel de oudste Philippe, als de jongste Guillaume, die na den dood zijns vaders geboren werd, betoonden zich hunner af komst waardig. $\mathrm{Zij}$ waren beide achtereenvolgens kolonel van het Waalsch Regiment, en gouverneur van Heusden. De eerste stierf in I625. GUILlaUme sneuvelde in I629 voor den Bosch. Beiden werden in de Groote Kerk te Heusden bijgezet in den grafkelder, waar ook het stoffelijk overschot huns vaders rustte. Aan GuILlaumE's weduwe ANNA MARIA BERCK (zij was vroeger weduwe van den vermaarden ritmeester MARCELIS BAX), die geheel onbemiddeld achterbleef met hare kinderen, werd door de Staten Generaal een pensioen van $f$ 600.- per jaar toegekend, op aanbeveling van Prins FREDERIK HeNDRIK en den Raad van State. Dat men toen de groote diensten, door den vader bewezen, nog niet vergeten had, moge blijken uit de bewoordingen, waarin dat pensioen door de Staten Generaal werd toegekend: "Considererende dat nyet alleen de voorsz. Colonel (GuILLAume DE FAMARS) is s' Landts dienste gestorven is, maer dat hij van eenen Vader gecomen in ende eenen Broeder gehadt heeft, beyde Edelluyden die hun nyet ontsien en hebben goet ende bloet voor 't Landt op te setten, ende daerdeur hun huys ende naecomelingen inde tegenwoordige groote ongelegentheyt te stellen, ende daerbenevens in achtinge nemende de redenen inde favorable recommandatien van Syn Ex $x^{\text {cie }}$ verhaelt, soo meijnen sy dat tselver wel eenige extraordinarise gunste meriteert." (Resol. Staten Generaal 29 October 1629.)

1) Brlef van den Raad van State aan de Staten Generaal van I Augustus 1592, voorkomende in het Register der brieven ingekomen uyt diversche plaetsen a ${ }^{\circ}$ I592 M. S. Rjjksarchief.

2) Resolutie Staten Generaal 24 November 1592. 
No. 43 I qq. (Cat. I 887 no. 937). Het opschrift luidt: Monsieur de Betune.

De Catalogus I 880 veronderstelt, dat dit het portret is van den bekenden staatsman PhILIPPE DE BEThune, die een rol speelde aan de hoven van HENDRIK IV en LoDEwIJK XIII van Frankrijk; denkelijk omdat dit de meest bekende Heer van Bethune is uit dit tijdvak. Van eene nauwe connectie tusschen Prins Maurits en dezen Philippe DE Bethune is mij echter niets gebleken. En toch mogen wij veronderstellen uit de reeks portretten, waartoe het behoort, dat het de afbeelding is van een der personen uit MAURITS' onmiddelijke omgeving, en waarschijnlijk een zijner legeraanvoerders.

Uitgaande van deze niet al te gewaagde veronderstelling, treffen wij een lid van het geslacht BETHUNE aan, dien ik meen voor den hier afgebeelden persoon te moeten houden, namelijk Syrius DE BETHUNE. Denkelijk kwam hij hier met zijn ouderen broeder LEONIDAS ${ }^{1}$ ), gelijk zoovele andere fransche edellieden als vrijwilliger, om den oorlog te leeren onder Prins MAUkITs. De eerste maal, dat wij Syrtus DE Bethune vermeld vinden, is in de Resolutiën van den Raad van State (Rljksarchief), toen hem den 2 Maart 1604 commissie werd verleend als kapitein. Den 24 November 1605 wordt hij kolonel over een fransch regiment in Statendienst, vacant gew orden door het sneuvelen van den Heer van Dommarville. In het Commissieboek der Staten Generaal I586-i625 f. $248^{8 v o}$, vindt men zijne aanstelling. Hij wordt daarin genoemd: Seigneur SYRIUS DE Berthune Chevãlier, Seigneur de Congi, Mareuil, le Beisil, Toulon, Conegory et Chastillon", al welke heerlijkheden hem bij den dood zijns broeders ten deel waren gevallen. Hij behoorde tot den aanzienlijksten franschen adel van de partij der Hugenoten. DUYCK (II p. 533) noemt zijn broeder "den heere van BuTHUNe uyten huyse van Melun, een neeff vanden heere van RHOSNy" 2).

Nadere levensbizonderheden over kolonel SyriUS DE BETHUnE zijn mij niet bekend. Hij was blijkens den Staat van Oorlog van I6Io (Rijksarchief), in dat jaar nog als kolonel in Staatschen dienst. Het portret is van omstreeks I6I 5 .

No. 43 I rr. (Cat. I 887 no. 945). Het opschrift luidt: Coronel Veer.

De Catalogus i 880 noemt hem Sir Francis VERE, die in 1602 bij de belegering van Grave sneuvelde (sic!) ${ }^{3}$ )

1) Leonidns werd 19 Augustús I601 kapitein (Doyck, III p. I03) en 25 April 1602 reeds kolonel ove een regiment fransche hulptroepen. Hij sneuvelde 1603 binnen Ostende.

2) MAximiliaAn van Bethune Baron van Rhosni, daarna Hertog van Sully, souverein vorst van Enrichemont en Boisbelle, grootmeester der artillerie, boezemvriend van HENDRIK IV $\dagger$ I64I.

8) Sir Francis VERE, de berocmde engelsche generaal, werd in dat beleg wel ernstig gekwctst, doch herstelde van zijne wonden. Bij besluit van 6 Juni 1606 legden de Staten Generaal hem een pensioen toe in $f$ b000.- 's jaars, voor de hoogst belangrjjke diensten door hem gedurende zo jaren aan de Nederłanden 
Dat wij hier evenwel het portret van zijn broeder SIR HORATIO VERE vóór ons hebben, blijkt duidelijk uit de afbeeldingen, die van beide broeders bestaan.

Behalve die, vermeld in v. Someren's, "Gegraveerde portretten", komen hun beider portretten voor in CLEMENTS R. MARKHAM "The fighting Veres", London I 888 . Een portret in olieverf van SIR FRANCIS VERE, borstbeeld, op jeugdigen leeftijd, gegraveerd door Faithorne, voor Dr. William Dillingham "The commentaries of Sir FRANCIS VERE", Cambridge 1657 , berust thans in de collectie van den Hertog van POR'Tland, te Welbeck. Sir Horatro VERE'S portret op rijperen leeftijd, borstbeeld, geschilderd door CORNELIS JANSSENS VAN Ceules, komt voor in de Collectie van den Markies Townshend, en is gegraveerd door VERTUE voor Collin's „Historical Collections of the Antient and Noble Family of VERE". Een ander portret, staande ten voeten uit, eveneens aan Cornelis Janssens van Ceulen toegeschreven, is in het bezit van Sir $H$. ST. JOHN Mildmay.

Er bestaan dus afbeeldingen genoeg van de beide broeders, om niet in twijfel te behoeven verkeeren, dat wij hier wel degelijk met het portret van SIR Horatio Vere, en niet met dat van Sir Francis Vere te doen hebben.

Er zijn zoo vele en uitvoerige levensbeschrijvingen van SIR HORATIO VERE, dat wij daarop hier niet verder zullen ingaan.

Zijne commissie als generaal over de engelsche compagniën te velde van 3 Mei 1605 vond ik in het Commissieboek der Staten-Generaal 1586-1625 f. 247. Voorts trof ik nog de volgende aardige bizonderheid omtrent hem aan: Toen Karel I den engelschen troon beklom, werd Sir Horatio Vere tot Pair verheven met den titel Lord VERE of TILBURY. De schildhouders van het hem daarbij verleend wapen waren : rechts, een everzwijn (het oude helmteeken der VERES), op de borst afhangend een schildje met het wapen van Holland; en links eene harpij met een schild waarop het Zeeuwsche wapen; eene onderscheiding, ten volle verdiend door den dapperen krijgsman, die sedert I 590 met grooten roem de Vereenigde Provinciën had gediend, met vele andere leden van zijn geslacht. ${ }^{1}$ )

bewezen. Hij overleed te Londen 28 Augustu; Ifog. Ten onrechte vermelden alle biographien van hem, dat hij 28 Aug. 1608 stierf, afgaande op het grafschrift op zijn monument in de Westminster Abdij. Blijkens het begrafenisregister der Abdij, een brief van Sir FrANcrs den dag vóór zijn dood, 27 Aug. I6og uit Portsmouth geschreven, en andere officieele stukken, is hij werkelijk den 28 Aug. 1609 gestorven.

Het kostbaar grafmonument is geheel eene navolging van dat van ENGELBRECHT II van Nassau in de kerk te Breda.

1) Niet minder dan tien leden van dit heldengeslacht streden en stortten hun bloed voor Nederland's onafhankelijkheid. ROBERT Vere, broeder van Sir HoRatio, sneuvelde in I595, HENRY Vere, I8e graaf van Oxford, overleed aan de verwondingen bekomen in het beleg van Breda in I624, Sir EDWARD sneuvelde I6a9 in het beleg van den Bosch, ROBERT VERE, Ige graaf van Oxford, en EDWARD VERE bleven in I 632 in het beleg van Maastricht, terwijl Sir FrancIs en Sir HorAtio letterlijk gekorven waren. Sir Francis had alleen vijften wonden bekomen. 
Kort na de inneming van Maastricht in 1632 keerde hij voor goed naar zijn vaderland terug, waar hij 2 Mei ${ }^{6} 635$ in zijn 7 oste jaar overleed. Den 8 Mei werd hij met groote praal in de Westminster Abdy begraven in hetzelfde graf, waarin het stoffelijk overschot zijns broeders FRANCIS was bijgezet.

No. 43 I ss (Cat. I 887 no. I I 89). Het opschrift luidt: Coronel Hendersom.

No. 431 tt (Cat. I887 no. I I90). Het opschrift luidt: Colonel Brock.

De Catalogus 1880 vermeldt alleen, dat VONDEL in zijne "Veroveringh van Grol door FREDERIK HENRIK" onder 's prinsen legeraanvoerders ook „BROCK en Hendersum" noemt.

De samensteiler van dien Catalogus schijnt, naar het mij voorkomt, zijn licht slechts ontstoken te bebben bij V. D. AA. "Biographisch Woordenboek" en dergelijke encyclopaedische werken; en waar deze hem, gelijk hier het geval was, geheel in den steek lieten, heeft hij waarschijnlijk geen kans gezien over deze twee kolonels iets naders mede te deelen, althans, wat hij geeft, is zóó mager, dat wij de letters ss en $t$, waarmede zij in den Catalogus zijn aangegeven, maar voor de gebruikelijke afkorting van "salvis titulis" zullen houden.

Een nader onderzoek in het Rijksarchief, aangevuld met de aanteekeningen, die ik reeds vroeger elders maakte, stelt $\mathrm{mij}$ in staat van beiden een vrij nauwkeurig levensbericht te geven.

Sir Robert Henderson of TunNegask, zoon van James Henderson (of: Henrysone) Baron van Fordell, en Jeanne Murray (dochter van Sir Andrew MURRay Baron van Tullibardine), was gesproten uit een oud adellijk schotsch geslacht. Gelijk zoo vele jongere zonen van edelen schotschen stam, begaf hij zich in vreemden krijgsdienst en voegde zich bij de Schotsche Brigade, die reeds van af den aanvang van den 8ojarigen oorlog in nederlandschen dienst was ${ }^{1}$ ).

In een der laatste jaren van de $I \sigma_{e}$ eeuw werd hij luitenant van de compagnie van kolonel Sir Alexander Murray (of Tullibardine), die het bevel

1) Reeds in 1572 waren Schotten in dienst van den Prins van ORANJE. In den winter van dat jaar trokken zij, onder aanvoering van kapitein BALFoUR, over de bevroren Haarlemmermeer binnen Haarlem, tot versterking van het garnizoen der belegerde veste (v. Meteren uitg. I6I4 $f^{\prime} 87^{\prime}$ ). En tot het jaar 1783 bleef de Schotsche Brigade bier te lande.

Geen wonder dat de 8ojarige oorlog, waarin duizenden Schotten het leven lieten, nog in menige schotsche ballade herdacht wordt. Hier volgen twee coupletten uit twee oude balladen:

Oh, woe unto those cruel wars

That ever they began,

For they have swept my native shore Of many a pretty man :

For first they took my brethren twain,

Then wiled my love frae me.

$\mathrm{Oh}$, woe unto those cruel wars

In Low Germanie !
Repent it will I never

Until the day I dee,

Though the Lowlands o'Holland

Hae twined my love and me. 
voerde over de Schotsche Brigade. Na diens sneuvelen in het beleg van Bommel werd HeNDERSON door den Raad van State op I5 Juni 1599 aangesteld tot kapitein over de compagnie ${ }^{1}$ ) van genoemden kolonel (Commissieboek R. v. St. Eedboek fo. Io Rijksarchief.) Den 20 December 1603 werd hij benoemd tot luitenantkolonel van het juist nieuw aangeworven regiment Schotten van kolonel Sir WALTER SCOTT of Buccleuch, na wiens overlijden hij den 5 Febr. I6I4 kolonel over bedoeld regiment werd. ${ }^{2}$ ) $\mathrm{Hij}$ was een man van buitengewonen moed, en met zijne stoere Schotten verrichtte hij wonderen van dapperheid. Tijdens het beleg van Bergen-op-Zoom in den nacht van I6 Augustus 1622 werd hij doodelijk gekwetst. Aitsema I fo. I I $9^{\text {a }}$ bericht daaromtrent het volgende:

„De colonel Hinderson was niet tevreden self in persoon sich in dese halve maen te vinden: maer om te meer couragie ende goet exempel te geven, hielt sich voor aen op het Parapet van 't half maentje: tot dat door een musquet Kogel het been van sijn Dije stucken geschooten, ende hij swaer gewapent ter aerden geworpen wierdt; leggende, ende gheroepen wordende: „Onsen Colonel is doot", soo sprack hy mannelyck: ,ick ben niet doot, schiet, schiet en avanceert lustich". Colonel Hindersson lict sich terstont na de quetsure afdragen ence door Raet van de Medicijns na den Hage voeren: alwaer hij korts daernae gestorven ende met het heerlyck symb, van „Pulchrumque mori succurrit in armis” boven zijn blasoen gestelt, begraven ende seer beklaeght is."

Hij werd in de Groote Kerk aldaar begraven ${ }^{3}$ ).

Sir RobERT was gehuwd met ANNA KIRKPATRICK, 4) dochter van kapitein JOHN KIRKPATRICK (die met zijn zoon, den vaandrig THOMAS KIRKPATRICK, in den voor de Schotten zoo noodlottigen, doch roemvollen strijd bij Leffinghem den 2 Juli itoo gesneuveld was), en Elisabetir Greir (dochter van GuthBert Greir Heer van Dalgumer). Hun zoon JAmes HENDERSON ${ }^{5}$ ) was luitenant-kolonel in het regiment zijns vaders, waarvan het commando bij diens dood was overgegaan op diens broeder Sir Francis Henderson, blijkens resolutie der Staten-Generaal van 17 September I622 (Eedboek fo: 57 ).

1) Destijds had een kolonel steeds zelf eene compagnie in zijn eigen regiment, waarover de luitenant als kapitein het bevel voerde, de zoogenaamde "compagnie colonelle".

2) Commissieboek Staten General $x_{5} 86-I 625$ fo, 297 .

3) Grafboeken der Groote of St. Jacobskerk, medegedeeld in Algem. Nederl. Famiiieblad XI p. 208.

4) Zie het belangrijk handschrift Doys, bewaard in de Bibliotheek van het Gerechtshof te Leeuwarden, i. v. Kirkpatrick.

5) Een adelbrief, ten zijnen behoeve door koning KAREL I den 26 Januari 1637 te Edinburgh afgegeven voor den "vice-tribunum (luit.-kolonel) JACOBUM HenRysone nunc in Germania degentem", werd door de firma FRFD. MULLER \& Co. te Amsterdam op de aldaar in 1896 gehouden tentoonsteliing in "Oud-Holland" geexposeerd, en later in eene publieke veiling verkocht. JAMEs werd blijkens de Grafboeken der Groote Kerk te 's Hage den 6 Juli $163^{8}$ in den grafkelder, waar ook zijn vader rustte, begraven, en werd $7 \mathrm{~J} u$ li $163^{8}$ als luit.-kolonel opgevolgd door ArChibald Douglas (Resolutien Raad van State). 
Sir WiLliam BROG behoorde eveneens tot een adellijk Schotsch geslacht. De eerste maal, dat $\mathrm{ik}$ zijn naam aantref in de archieven, is $12 \mathrm{Juli} 1588$, toen "den manhaften GuILliam BROG" door den Raad van State commissie werd verleend als sergeant-majoor ${ }^{1}$ ) "over den schotsen crychsvolcke ende Regimente onder den Colonnel BALFOUR ende andere schotse capiteijnen in der Landen dienste wesende". (Commissieboek Raad v. State). Den 30 Maart I 590 verkreeg hij zijne aanstelling als kapitein over eene compagnie voetknechten. In 1594 in het beleg van Groningen werd hij gekwetst (DuYcK, I p. 426). In het volgend jaar, toen de Schotsche Brigade met een zeeuwsch regiment, onder Justinus van Nassau, naar Frankrijk den Koning te hulp werd gezonden, werd BROG door de Staten Generaal gecommitteerd, bij besluit van 27 September I 595, om dienst te doen als Sergeant-majoor over beide regimenten, ${ }^{2}$ ) en nam hij deel aan het beleg van La Fère.

$\mathrm{Na}$ de verovering dier stad, in Juli van het volgend jaar teruggekeerd, werd BROG met zijne compagnie en drie andere schotsche vendels reeds den 2 Augustus daarop door FREDERIK HENDrik binnen Hulst gezonden, dat door den vijand belegerd werd, en door de onbekwame leiding van den graaf van SoLMS in grooten nood verkeerde, waardoor de bezetting den moed opgegeven had. Den volgenden dag vermeesterden de Spanjaarden het ravelijn, doch werden daaruit door de belegerden terstond weer verdreven, „daerinne de Schotten te vooren in stadt gecommen, heur seer wel queten ende bijnaest alle de anderen thart onder den riem staken". (Duyck II p. 94). De slechte leiding der verdediging was echter oorzaak, dat de bezetting hoe langer hoe mismoediger werd, en door den krijgsraad tot capitulatie werd besloten. Toch deed de dappere BRoG met zijne Schotten nog een uitval op den vijand, die reeds tegen den wal aanlag, en verjoeg hem vandaar. Den 28 Augustus 1596 gaf de stad zich over, hetgeen den graaf van Solms door de Staten van Zeeland zoo euvel geduid werd, dat zij hem uit hunnen bijzonderen dienst ontsloegen. Onder de vier officieren, aan wie de Raad van State eene enquête opdroeg naar het gedrag van den Graaf, bevond zich ook kapitein BROG (DUYCK, II p. I4 I).

In 1597 nam hij deel aan de verovering van Rijnberk, Grol, Breêvoort, Oldenzaal en Lingen. In 1599 bevond hij zich binnen Bommel tijdens het beleg, en toen de schotsche kolonel Sir Alexander Murray, die het bevel binnen de vesting voerde, door een kanonskogel op den wal sneuvelde, richtte BroG tot de Staten-Generaal het verzoek, als zijnde een der oudste kapiteins, MURRAY in het

1) Een rang ongeveer gelijkstaande met het tegenwoordige kapitein-adjudant.

2 Commissieboek Staten Generaal ${ }_{5} 86-1625$ fo. $116^{\circ 0}$.

Oud-Holland, I 898 . 
Commando als kolonel op te volgen. Zijn verzoek werd schriftelijk ondersteund door de Gedeputeerden te Velde en den Magistraat van Bommel, die hemaanbevalen wegens zijn moedig gedrag en zijne vele dienstjaren. ${ }^{1}$ ) De Prins had inmiddels reeds den ritmeester GUILlaUME EDMONT voor de vacature aanbevolen, die ook reeds vele jaren in dienst der Staten geweest was; en deze werd tot kolonel benoemd. In het moorddadig gevecht bij Leffinghem op 2 Juli I600, waarbij het schotsche regiment in den strijd tegen het geheele spaansche leger bijna totaal werd vernietigd, ontving BROG zware kwetsuren. Docr deze zelfopoffering der Schotten 2) kreeg MAURITS evenwel tijd om zijn geheele leger bij laag water door de haven van Nieuwpoort te doen trekken, en eene gunstige stelling tegen den naderenden vijand in te nemen, waardoor de schitterende overwinning op de Spanjaarden mogelijk werd. In 's Rijks Prentenkabinet te Amsterdam bevindt zich eene prent van Floris Balthasarsz (door MUller in diens Nederl. Historieplaten onder no. II 33 de zeldzaamste van alle historieplaten genoemd), voorstellende de „clades Scotorum in Flandria Anno I600 pro salute totius exercitus fortiter occumbentium". Van de aan den strijd deelnemende I I schotsche kapitcins, I I luitenants en 12 vaandrigs sneuvelden 7 kapiteins, Io luitenants en II vaandrigs, terwijl zij die het leven er af brachten, meestal gewond waren. Omstreeks zes honderd Schotten bleven op het slagveld.

Nadat inmiddels door aanwerving in Schotland de Brigade weer voltallig gemaakt was, werd BRoG den 3 Januari r6or bij resolutie van den Raad van State tot luitenant-kolonel daarbij aangesteld, en trok hij met zijne compagnie het belegerd Ostende binnen. Den Io September I60I, met den jongen graaf Henri van Colligny en kolonel van HuCHTENBRouck en eenige kapiteins zich op het bastion Zandhil bevindende, om het voorgelegen terrein met het bog op een tegen den volgenden dag beraamden uitval in oogenschouw te nemen, nam een kanonskogel het bovengedeelte van Colligny's hoofd weg, waarvan Huchtenbrouck een gedeelte in het gelaat kreeg; "maer een stuck van sijn panne van ongewoenlijcke dickte vlooch den lieutenant Colonel BROG onder den ooge over de wang inne, morselende sijn neus ende alle het wangebeen ende soo diep schietende, dat hij daeraf in doots pericule was"; (DUYCK, III p. I53,4); "daervan hy noch de litteeckenen draecht", zegt FLEMING (Oostende, p. II2). Op ons portret is dit lidteeken duidelijk zichtbaar. Den I 8 September werd hij geëvacueerd naar Zeeland. Na gelukkig van zijne wonden hersteld te zijn, kwam hij 29 Maart 1603

1) Register van brieven ngekomen uyt diversche plaetsen a.. I599 I fo. 484-5.

2) Niet geheel ten onrechte vergelijkt DE LA PISE in zijn ${ }_{n}$ Tableau de l'histoire des Princes et Principautés d'Orange" deze zelfopoffering der Schotten met het gedrag der Spartanen bij Thermopylae. 
weer binnen Ostende, waar hij zich als kommandant der oude schotse compagniën zoodanig onderscheidde, dat hij, toen kolonel EDMONT in I 6 c6 bij het beleg van Rijnberk gesneuveld was, den 12 September van dat jaar tot kolonel over het Oude $^{1}$ ) Schotsche regiment werd benoemd. (Resolutiën Staten Generaal to. 260).

Het zou ons te ver voeren, wanneer wij kolonel BROG op zijne schitterende loopbaan aan het hoofd zijner dapperen overal wilden volgen. Hij nam deel aan alle belangrijke krijgsbedrijven van zijnen tijd en steeds vinden wij zijn naam met eere genoemd, vooral in de belegeringen van Grol (1627) ${ }^{2}$ ), den Bosch (1629) en Maastricht ( $16_{32}$ ). En dat FrEUERIK HENDRIK bij het beleg van den Bosch de Schotsche Brigade "het bolwerk van de Republiek" noemde, daaraan had zeker geen gering aandeel de onverschrokkenheid en trouw van kolonel Broc.

Den 4 Maart 1636 werd de grijze soldaat, na den lande gedurende ongeveer 50 jaren gediend te hebben, in de Groote Kerk te 's Hage bijgezet. (Grafboeken dier kerk, Algem. Nederl. Familieblad XI p. 25 I).

In een zeldzaam voorkomend werk getiteld "Eenige formen van SlachOrdens soo ten deele als in 't geheel van de Legers der Geunieërde Provinciën, Geordineert bij Mauritius en Fredrick Henrick'. 's Hage. H. Hondius, i638, kl. fol. komt een portret voor van "WILH. BROG Ridder en Koronel van de Schotsche Natie. Ao. I635" door C. V. QUeboren. (Niet vermeld in Fred. Mullek's Cat. van 7000 Portretten en v. SOMEREN's vervolg).

Ons portret van BROG is, evenals dat van ROBERT HENDERSON, van circa 16 I 5 .

No. 43 I uu. (Cat. I 887 no. 983). Het opschrift luidt: Coronel Wijten Hoghe.

Met dezen naam heeft de samensteller van den Catalogus blijkbaar geen raad geweten, althans elke toelichting is achterwege gebleven.

Toch is het geenszins twijfelachtig, wie dit portret voorstelt. Het is kolonel ANTHONIE VAN UTENHOVE (waarschijnlijk heeft er oorspronkelijk op het portret gestaan: Vurtenhove, naar de oude schrijfwijze). Elke mogelijke twijfel wordt opgeheven door de gravure, voorkomende in FLEming's OOSTENDE, die eene sprekende gelijkenis met dit portret vertoont.

1) In het laatst van het iaar I603 werd een nieuw regiment Schotten gelicht door Sir WALTER SCoTT of Buccleuch.

2) Vonder, in zijn "Verovering van Grol" noemt de kolonels Brog, Francis HeNderson (broeder van no. $43 \mathrm{I}$ ss) en Horatio Vere onder Frederik Hendriks voomaanste aanvoerders bij dat beleg:

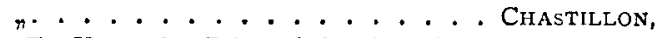

"En VEeR der Britten helm, beschittert van de zon,"

"BRock, Cissel, Hendersum die lof voor leven kiezen".

(Crssel, geschreven zooals de naam wordt uitgesproken, is Edward CECIL, engelsch kolonel.) 
Hij was gesproten uit een der oudste en edelste geslachten der stad Gent, dat vooral in de $I 6$ e eeuw vele geleerde mannen voortbracht en, door zijn ijveren voor de Hervorming, meer dan eenig ander aan de vervolgingen der inquisitie was blootgesteld. Meerdere leden dezer familie onderteekenden het compromis der edelen. Een hunner, ANTHONIE, (een naamgenoot van den Kolonel), behoorde tot cle aanvoerders der Watergeuzen die den Briel innamen, en eindigde zijn leven op den brandstapel (Brussel 22 Augustus I572). Alle bezittingen van dit rijke geslacht werden verbeurd verklaard. De oudste tak, waartoe de kolonel behoort, ${ }^{1}$ ) werd in het midden der 16 e eeuw uit Vlaanderen verbannen, en schijnt den wijk genomen te hebben naar de Palts, waar Olivier UTENHOve in 558 in hei huwelijk trad met Elisabeti Kethel van Hacfort, dochter van ANTHonie, Raad van den Hertog van Gelre, en Elisabeth (of: Machthld) Mulert. Uit dit huwelijk werd de latere kolonel ANTHONIE (VAN) UTENHOVE geboren. In September I 595 kapitein geworden over eene compagnie voetknechten, maakte hij eene zeer snelle promotie, voornamelijk door zijn heldhaftig gedrag binnen Ostende, tijdens het wereldvermaard beleg. Gedurende bijna drie jaren was hij in de belegerde vesting. Na het sneuvelen van den zevenden gouverneur JACOB VAN DER MEER VAN BERENDRECHT, genoot Utenhove, die inmiddels reeds tot kolonel opgeklommen was, de eer met het gouverneurschap te worden belast. Den I 7 Juni 1604 geschiedde een der meest verwoede aanvallen, die in dit aan dagelijksche gevechten zoo rijk beleg plaats grepen. Met leeuwenmoed verdedigde de gouverneur in persoon de bres, om de zijnen des te meer moed in te boezemen. En de aanval der Spanjaarden werd afgeslagen, doch ten koste van stroomen bloeds. In een uur tijds waren van beide kanten 600 man gesneuveld, die in de bres opgehoopt lagen en waarvan men zich als van eene borstwering bediende. In het heetst van den strijd ontving UTENIOVE "doende seer eerlyck sijn devoir" een schot in de hals, en stortte in zijne zware wapenrusting ter aarde. "Eenighe Engelsche als andere sulcx siende, hebben hem terstont met die beenen ghenomen ende uyt die Bresse getrocken, ende soo hert, ghewapent zijnde, vant Bollewerck ghesleypt, overhoop roepende den Gouverneur is doot. Ick Auditeur daer present zijnde en siende datse den Commandeur so onmenschelyck tracteerden ende van meyninghe waren om hem te plunderen, bense vant Bollewerck naer gheloopen ende met assistentie van vele Officieren ende soldaten die hem so sleypten van daer ghedreven.

1) Ten onrechte zegt SyPEsteyn (Het merkwaardig beleg van Ostende p. 94 noot), dat hij de kleinzoon was van KAREL UTENHOVE, den beroemden burgemeester van Gent, onderteekenaar van het verbond der edelen. Deze KAREL behoorde tot den jongeren tak, die het wapen UTENHove voerde, gebroken met den barensieel. Des kolonels grootvader was JAN UTEnhove Gijsbrechtszoon, in 1505 secretaris, in 1509 , 14 en 22 schepen van Gent, gehuwd met Jacqueline de Calf LaUrenspr. 
Syn Casquet wert hem tcrstont vant hooft ghenomen, om te besien oft hem die quetsure die doot hadde ghedaen, maer ghelyck hij die locht ghevoelende, wierden ghewaer dat hy synen asem noch verhaelde, waer over hij terstont met groote droefheyt nae syn logement ghebracht wert. Onghetwijffelijck, hadden die voorgaende hem met die beenen ghecontinueert soo te sleypen, souden seeckerlijck om 't leven ghecomen hebben' (FLEMING, Oostende p. 555).

Onmiddelijk werd hij geëvacueerd; en hoewel hij nog largen tijd in levensgevaar verkeerde, herstelde hij toch langzaam. In 1606 werd hij gouverneur van Doesburg, en daarna van Emmerik. Hij overleed begin December I625. In eerste huwelijk was hij getrouwd met AGNes VAN ReNESSE VAN BAER, vrouwe van Rijnestein, die stierf binnen Doesburg den I I November I6I3. Het volgende jaar. huwde hij JOHANNA vax BERFELD, dochter van kapitein CHRISTIAAN BERFELd en Elisabeth Bentinck. Bij zijne eerste vrouw had hij 5, bij de tweede 2 kinderen. Hoezeer hij in aanzien was, moge hieruit blijken, dat over zijne twee laatste kinderen de keurvorst van Brandenburg en de Staten van Utrecht als peter stonden.

Vele brieven van hem bevinden zich in het Rijksarchief te 's Hage.

No. 43 I vv. (Cat. I887 no. I I9I). Het opschrift luidt: D'Heer van Kessel. Ook omtrent hem geeft de Catalogus geene nadere inlichtingen.

Het is de beeltenis van Willem AdriaAN GraAf van Hornes, Heer van Kessel, Woestwezel enz., zoon van JAN II Graaf van HORNEs, Baron van Boxtel en Bauciognies, Feer van Lokeren enz., on diens tweede gemalin ANNA VAN FLODORP (dochter van Balthasar Heer van Lugt).

Den 22 December I 603 werd de Heere van KESSEL door de Staten-Gencraal benoemd tot generaal der artillerie der Vereenigde Nederlanden ("die hem daer te vooren daerinne behoorlyck hadde gequeten binnen de Stadt van Oistende". Resol. Staten-Generaal). Later werd hij ook gouverneur van Heusden. Hij overleed in 1625. Hij was twee maal gehuwd. Zijne eerste vrouw was Is $\triangle$ BELLA VAN DER MeEREN, vrouwe van Woestwezel (dochter van PHILIPPUS Heer van Sterrebeeck en Saventhem). Hij trouwde daarna DOROthea van HAEfTEN.

Zijn zoon JAN vaN HORNEs, zoowel als zijn kleinzoon WiLlem AdRIAAN, Baronnen van Kessel en Batenburg, waren beide generaal der artillerie. Ten onrechte vermeldt VAN DER AA, Biogr. Woordenboek, dat WILlEM ADRIAAN (de oude) 's portret door Joseph GREUTER zou gegraveerd zijn. Hij verwart hem daar met Willem DE HoRnes, Heer van Heze, Linden, Geldrop enz., die 8 November i 580 op last van FARNESE onthoofd werd. 
Ten slotte nog eene rectificatic van de toeschrijving van een portret, wel is waar niet tot deze serie behoorende, doch daaraan toch nauw verwant, daar het een officier uit hetzelfde tijdvak voorstelt.

In de Admiralen-zaal juist boven de portretjes van het Huis Honselaersdijk, hangt een levensgroot kniestuk van "CAPTEIJN RIPPERDA" (gelijk in den achtergrond geschilderd staat), geschilderd door een onbekend meester in den aanvang der $17^{\mathrm{e}}$ eeuw. (Cat. $1880 \mathrm{n}^{\circ} .438$, Cat. I 887 no. 56I).

Volgens den Catalogus is dit portret, als van FRANS HALS, afkomstig uit het nationaal Museum te 's Hage 1808 , en stelt het voor WIGBOLT RIPPERDA, den dapperen verdediger van Haarlem tijdens het beleg, die Io Juli 1573 door de Spanjaarden onthoofd werd.

Beide opgaven zijn onjuist. Het is nooit toegeschreven aan FRANS HaLS en stelt niet voor WIGBOLT RIPPERDA.

AD Ium. Het portret stond vroeger niet ten name van Frans Hals.

In vroegere catalogi van het museum vindt men twee portretten van kapitein RIPPERDA, het eerste ten name van Frans HALS, het tweede onder ,onbekende meesters". Dat van FR. HALS komt voor in de verschillende uitgaven van den Catalogus verschenen tusschen 1809 en I843, als het portret van RIPPERDA. De catalogus van 1846 noemt hem niet meer kapitein RIPPERDA, doch spreekt slechts van "een mansportret". Men was toen teruggekomen van de oude attributie, hetgeen zeker niemand verwonderen zal, wanneer hij weet dat het vroegere portret van kapitein RIPPERDA niets anders is dan no. 443 van den Catalogus 1887 ,een vroolijk man" van FRANS HALs, thans een der juweelen van de collectie.

In den Groningschen Volksalmanak van I839 vindt men eene bijdrage over Wigbolt RIPPERDA, den kommandant van Haarlem in $1572 / 73$, van de hand van mr. T. P. TREsLING, waarbij deze eene lithographie geeft naar FraNs HALS ,portret van RIPPERDA in het Rijksmuseum". "Het is ons een wellust", s chrijft mr. TRESLING, "door het plaatsen der afbeelding van WigBolt RIPPERDA na ar de schilderij van Frans HALS in het Rijksmuseum te Amsterdam, eene wel$v$ erdiende hulde aan zijne nagedachtenis toe te brengen". En hij gaat, op gezag van den Catalogus, den vroolijken, lustigen drinkebroer, die blijkbaar reeds diep in het glas gekeken heeft, dat hij met de linkerhand omklemd houdt, der goê gemeent' voorstellen als RIPPERDA, den gouverneur van het belegerd Haarlem! Risum , tencatis ...! Men zou het kwalijk kunnen gelooven, dat deze schilderij ja ten voor RIPPERDA 's portret heeft gegolden, en eerder geneigd zijn te denken dat de een of andere grappenmaker mr. TRESLING in 't ootje genomen had, zoo niet de fransche uitgave van den Catalogus van 1836 elken twijfel ophief, door 
het stuk te beschrijven als: „Fr. Hals portrait en ébauche du capitaine RIPPERDA”. Hiermede is dus wel degelijk het ietwat schetsachtig behandeld meesterstuk no. 443 van Frans HaLs bedoeld.

Het tweede portret, dat WigBolt RIPPERDA heette voor te stelien, en dat voor het eerst in den Catalogus van I 827 vermeld wordt, bleef sedert onder de stukken van onbekende meesters op dien naam staan, en is het tegenwoordige $\mathrm{N}_{0}$. 56I. Ten onrechte vermeldt de Catalogus 1880 dus, dat dit portret vroeger aan Frans Hals werd toegeschreven.

En hoe is het feit, dat Frans HaLs "Vroolijke man" reeds in den Catalogus van I 809 voorkomt (als het portret van kapt. RIPPERDA), te rijmen met de opgave in den Cat. I880, dat het werd aangekocht op de veiling Bsse VAN LEYDE, Leiden 1816 ?

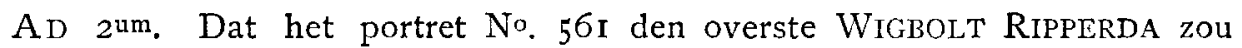
voorstellen, die reeds in 1573 overleden is, komt mij, zonclere nadere bewijzen, onaannemclijk voor.

Immers, het kostuum is geheel dat van onstreeks 1615 .

In den achtergrond leest men slechts "capteyn RIPPERDA", zonder eenige nadere aanduiding, welk lid het is van dit oud adellijk Groningsch geslacht.

Mijns inziens ligt het dus voor de hand, dat het de afbeelding is van een kapitein RIPPERDA, die in het begin van de $17^{\text {e }}$ eeuw leefde.

Uit de Staten van Oorlog van dien tijd (Rijksarchief) blijkt, dat er drie kapiteins van dien naam in het Statenleger dienden, n.l. Focco, Unico en EGgERICH ADRIAEN.

Focco RIPPERDA komt in de Staten van Ooriog I599-1617 voor als kapitein ter repartitie van Friesland;

UnICO RIPPERDA in de Staten van Oorlog $1609-16 \mathrm{I} 3$ als kapitein ter repartitie van Overijssel, daarna als ritmeester;

terwijl EgGERICH ADRIAEN RIPPER DA in I6I7 mede als kapitein ter repartitie van Overijssel voorkomt.

Ongetwijfeld stelt het portret No. 56I dus een der drie genoemde jonkers RIPPERDA voor.

De eerstvolgende Catalogus van het Rijksmuseum van schilderijen zal dus, gelijk de Catalogus van $\mathrm{i} 846$ reeds deed ten opzichte van het portret van Wigbolt Ripperda door Frans HaLS, thans ten tweedenmale den dapperen kommandant van Haarlem moeten verloochenen.

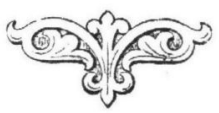

